\title{
Use of radionuclide angiography and an electrocardiographic stress test to diagnose multivessel disease after a first episode of uncomplicated myocardial infarction
}

\author{
ALBERTO FUBINI, * ENRICO CECCHI, * MARIA T SPINNLER,

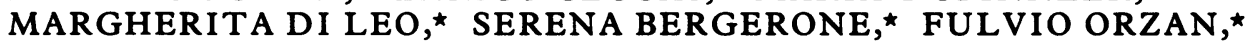 \\ PATRIZIA PRESBITERO, * PIERO MORELLO $\dagger$ GIANCARLO CASTELLANO,$\dagger$ \\ GIANLUIGI TURCO, $\uparrow$ ANTONINO BRUSCA ${ }^{\star}$ \\ From the $\star$ Istituto di Medicina e Chirurgia Cardiovascolare, and †Cattedra di Medicina Nucleare, Istituto di \\ Medicina Interna, Universitá di Torino, Turin, Italy
}

SUMMARY Sixty consecutive patients who were symptom free 2-12 months after an uncomplicated acute myocardial infarction underwent maximal treadmill exercise testing, radionuclide angiography before and during submaximal bicycle stress test, and coronary angiography. The results of the non-invasive procedures were compared with those of coronary angiography. The sensitivity and specificity of electrocardiogram stress test for detection of multivessel disease were $40 \%$ and $77 \%$ respectively. Failure of left ventricular ejection fraction to increase at least $5 \%$ with exercise identified 20 of the 25 patients with multivessel disease (sensitivity $80 \%$ ) and 23 of the 35 patients with no additional coronary antery stenosis (specificity $66 \%$ ). In patients with anterior $Q$ waves the sensitivity was $78 \%$ and the specificity $50 \%$, whereas in the presence of inferior $Q$ waves these values were $81 \%$ and $87 \%$ respectively. Loss of left ventricle synchronicity during effort, as indicated by failure of the standard deviation of the phases to decrease during exercise, demonstrated a radionuclide angiography sensitivity of $80 \%$ ( $77 \%$ for anterior myocardial infarction and $81 \%$ for inferior myocardial infarction) and a specificity of $50 \%$ (33\% for anterior myocardial infarction and $64 \%$ for inferior myocardial infarction). When the test was considered to be positive if either the ejection fraction or the standard deviation of the phases criteria were positive, the sensitivity was $100 \%$ and specificity $46 \%$ (30\% for anterior myocardial infarction and $65 \%$ for inferior myocardial infarction).

It is concluded that in patients who are free from angina 2-12 months after an episode of uncomplicated myocardial infarction, a simple exercise electrocardiogram cannot be relied upon to detect residual ischaemia. An abnormal ejection fraction response or an increased standard deviation of the phases during exercise nuclear angiography or both identified all the patients with multivessel disease. None of the patients in whom radionuclide angiographic criteria were negative had multivessel disease.

Several post-myocardial infarction risk stratification studies have identified three major variables related to subsequent coronary events: the extent of myocardial damage, residual coronary artery disease,

Requests for reprints to Professor A Brusca, Divisione Universitaria di Cardiologia, Corso Polonia 14, 10123 Turin, Italy.

Accepted for publication 7 January 1986 and the degree of electrical instability. ${ }^{1-3}$ In the first year after hospital discharge roughly $5 \%-10 \%$ of patients will die, $6 \%$ will experience a new episode of non-fatal myocardial infarction, and $16 \%$ will develop angina. ${ }^{4-6}$ Contrast ventriculography and coronary angiography have been widely used to evaluate the left ventricular function and the extent of coronary disease in post-myocardial infarction patients, and both have proved to be highly predic- 
tive of subsequent cardiac death, reinfarction, and angina. ${ }^{7-9}$

It is not practicable, or necessarily desirable, to recommend coronary arteriography to every patient recovering from myocardial infarction, especially when the clinical course is uncomplicated and the patient is symptom free.

Coronary angiography, however, is usually advised in younger patients and those with evidence of residual reversible myocardial ischaemia suggestive of additional coronary artery disease. We have assessed the value of exercise test and of exercise radionuclide angiography in detecting residual coronary arterial stenoses in such a group of patients.

\section{Patients and methods}

We studied sixty consecutive patients under the age of 60 years who were referred to our outpatient department 2-12 months after the diagnosis of uncomplicated myocardial infarction.

The diagnosis of myocardial infarction was based on the history of typical chest pain, the appearance of abnormal $Q$ waves or evolutionary ST-T changes, and an increase in cardiac enzymes. We excluded patients with residual resting and effort angina, congestive heart failure (S3, cardiomegaly, need for digitalis and diuretics), and valvar heart disease. Patients with a history of previous myocardial infarction were excluded because they were likely to have had coronary angiography. ${ }^{210}$

Cardioactive drugs were discontinued at least two days before the various tests. Each test was assessed by two investigators who were unaware of the results of the other two studies. The non-invasive tests were performed on two successive days; coronary angiography followed two days to two weeks later.

\section{ELECTROCARDIOGRAM}

The development of $\mathbf{Q}$ wave or loss of $R$ wave voltage $>50 \%$ in leads I, aVL, or V1-V6 was taken as evidence of anterior myocardial infarction (27 patients), and that in leads II, III, and aVF was taken to indicate an inferior myocardial infarction (33 patients).

\section{EXERCISE TESTING}

A maximal treadmill exercise test was performed according to the Bruce protocol. ${ }^{11}$ Twelve lead electrocardiograms were recorded before exercise with the patient supine and standing and during the Valsalva manoeuvre; and again after each minute of exercise, and 1, 3, 5, and 10 minutes after exercise, and at the onset of angina and a peak exercise. Exercise was stopped when any of the following occurred: incapacitating fatigue, dysponea or progressive angina, major arrhythmias (ventricular extrasystoles that increased during exercise, polymorphic ventricular extrasystoles, couplets, sustained or non-sustained ventricular tachycardia) or a systolic blood pressure drop of more than $15 \mathrm{~mm} \mathrm{Hg}$.

The test was deemed to be positive if angina occurred and/or horizontal or downsloping ST segment depression $>1 \mathrm{~mm}$ at $0.08 \mathrm{~s}$ after the $\mathrm{J}$ point in a non- $Q$ wave lead was recorded. In patients with resting ST-T segment abnormalities an additional shift of $1 \mathrm{~mm}$ or more was considered to be important. ${ }^{12}$

\section{CARDIAC CATHETERISATION}

Coronary angiography was performed in multiple projections. Left ventriculography was done in both left anterior oblique and right anterior oblique projections. Each patient had three, two, or single vessel disease. ${ }^{13}$ Coronary artery lesions with a luminal narrowing $\geqslant 70 \%$ in diameter were regarded as important. Where there were multiple stenoses of the same vessel only the most severe one was noted. Considerable narrowing in a large diagonal or obtuse marginal branch was recorded as left anterior descending and left circumflex disease respectively.

\section{RADIONUCLIDE ANGIOGRAPHY}

Radionuclide counts were acquired by the blood pool gating technique, with the patients at rest in upright position on the bicycle, at a stable heart rate. In our experience a count of 400000-600000 per frame is adequate; this can be done in five to eight minutes at rest. During the exercise test the workload was increased by $30 \mathrm{~W}$ every three minutes until $90 \%$ of the predicted maximal heart rate was attained. At this level the heart rate is steady and normal and abnormal ejection fraction responses to exercise can be easily identified. ${ }^{14}$ The count acquisition at submaximal exercise level was begun when a steady state was achieved and could not be prolonged for more than 4 minutes; this allowed us to acquire $150000-300000$ counts per frame.

Red blood cells were labelled in vivo with $15-20 \mathrm{mCi}$ of technetium- $99 \mathrm{~m}$, after administration of a stannous agent. ${ }^{15}$ We used a standard Anger camera equipped with a slant-hole collimator connected online to a dedicated minicomputer.

We used the left anterior oblique projection with craniocaudal tilt of $15-30^{\circ}$, which offers the best separation between atria and ventricles and between left and right ventricle.

Data were acquired in frame mode, $64 \times 64$ 
matrix, dividing the heart cycle in 16 equal intervals. Extrasystoles were rejected.

\section{ANALYSIS OF RADIONUCLIDE ANGIOGRAPHY VENTRICULOGRAMS}

The rough data were spatially smoothed by means of a conventional nine point convolutive filter (weights $4,2,1$ ), then a pixel by pixel discrete WalshHadamard transformation ${ }^{16}$ was applied to obtain phase and amplitude parametric images.

We used an interpolative method derived by Goris $e a^{17}$ based on the technique of the subtract background activity from the smoothed sequences. The left ventricular ejection fraction was calculated by a standard technique from the backgroundcorrected time-activity curve that was constructed over the diastolic region of interest of the left ventricle. Finally, we applied the left ventricular region of interest curve to the phase maps and calculated the mean value and the standard deviation of the phases by the Ratib et al procedure. ${ }^{18}$

\section{CRITERIA FOR POSITIVE RADIONUCLIDE ANGIOGRAPHIC TESTS}

The criteria for a positive radionuclide angiographic test were failure of left ventricular ejection fraction to increase by $\geqslant 5 \%$ on exercise and/or failure of the standard deviation of the phases to decrease during effort. We also investigated whether a positive result for either of the tests would have increased the detection of residual coronary arterial stenoses when the information that they provided was combined with the results of other tests.

\section{STATISTICAL ANALYSIS}

Data were stored on disc and analysed with the SAS package on a IBM 370 compatible computer system. The diagnostic success of the variables was calculated as sensitivity (true positive $\div$ (true positives + false negative)) and specificity (true negatives $\div$ (true negatives + false positives)). We used $\chi^{2}$ and Fisher's exact tests to assess the relation between the diagnostic tests and the results of coronary angiography. One way analysis of variance was applied for continuous variables in order to evaluate the differences between patient subgroups. A value of $\mathrm{p}<0.05$ was taken to be statistically significant.

\section{Results}

\section{ANGIOGRAPHIC FINDINGS}

Clinically unimportant lesions were found in four patients, and another patient had entirely normal coronary arteries (Table 1 ). Thirty patients (50\%) had important lesions or complete occlusion only of the infarct related coronary artery. We found multivessel disease in 25 patients (42\%); 18 had two vessel $(30 \%)$, six $(10 \%)$ had three vessel, and one had left main stem disease. We included the patient with left main stem disease, who also had a $50 \%$ lesion on the right coronary artery, in the three vessel group for statistical analysis.

Twenty nine patients had important lesions of the left anterior descending coronary artery, 15 had single vessel disease and 14 had multivessel disease.

Multivessel disease was more frequent in patients with inferior $Q$ waves $(45 \%)$ than in patients with anterior $Q$ waves (33.5\%), but the difference was not significant $(p<0 \cdot 1)$ (Table 1$)$.

\section{EXERCISE TEST}

Eighteen patients had a positive exercise test by electrocardiographic criteria; 10 of the 18 had multivessel disease. Forty two patients had a negative exercise test. Fifteen of them had multiple coronary stenoses, and they were regarded as false negatives. Thus this test had a sensitivity of $40 \%$ and specificity of $77 \%$ (Table 2). Only two of the seven patients with three vessel or left main coronary artery disease had a positive exercise test.

Of 27 patients with anterior $Q$ wave myocardial infarction, only four had a positive test; ST depression was present in the lateral leads of three and in the inferior leads of one. Additional coronary artery disease was present in only one (left anterior descending and right coronary artery). Thus in this group sensitivity was $11 \%$ and specificity was $83 \%$ (Table 2).

In patients with inferior $Q$ wave myocardial infarction sensitivity was $56 \%$ and specificity $\mathbf{7 0} \%$ (Table 2).

\section{RADIONUCLIDE ANGIOGRAPHY FINDINGS}

The radionuclide angiographic test was positive by the ejection fraction criterion alone in 20 of the 25 patients with multivessel disease (sensitivity $80 \%$ ) and negative in 23 of the 35 patients with no addi-

Table 1 Results of coronary angiography

\begin{tabular}{lllr}
\hline Myocardial infarction & 0 vessel & 1 vessel & 2 vessel \\
\hline Anterior & $3(11 \%)$ & $15(56 \%)$ & $6(22 \%)$ \\
Inferior & $2(6 \%)$ & $15(46 \%)$ & $12(36 \%)$ \\
Total & $5(8 \%)$ & $30(50 \%)$ & $18(30 \%)$ \\
\hline
\end{tabular}


Table 2 Results of exercise test

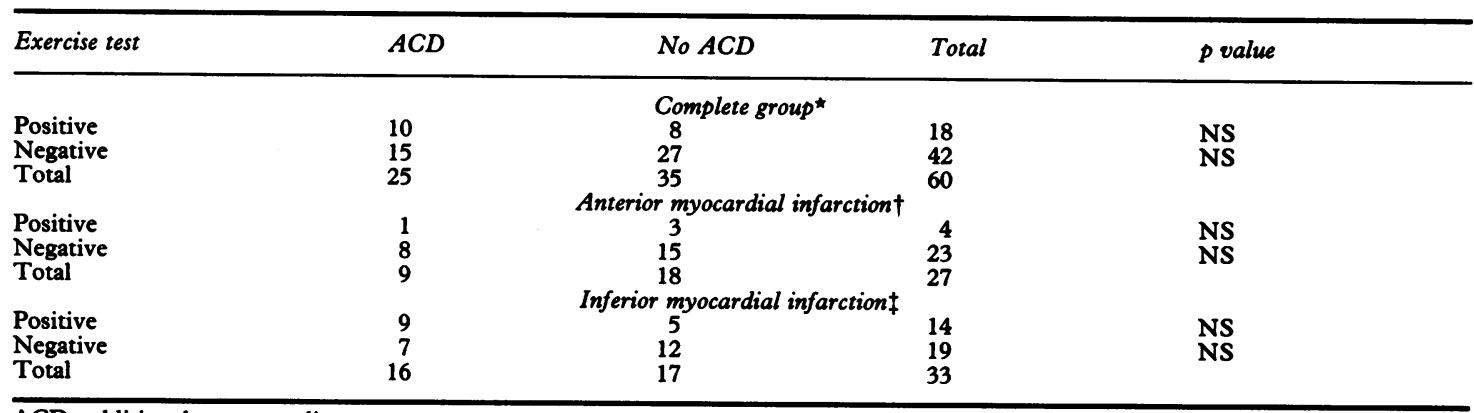

ACD, additional coronary disease.

$\star$ Sensitivity, $\mathbf{4 0} \%$; specificity, $77 \%$.

† Sensitivity, $11 \%$; specificity, $83 \%$.

¥Sensitivity, $56 \%$; specificity, $70 \%$.

Table 3 Results of radionuclide angiography and ventriculography as related to coronary angiography

\begin{tabular}{lccccc}
\hline & No ACD & ACD & Sensitivity & Specificity & $p$ \\
\hline Ejection fraction: & $23 / 35$ & $20 / 25$ & $83 \%$ & $66 \%$ & $<0.001$ \\
Anterior MI & $9 / 18$ & $7 / 9$ & $78 \%$ & $50 \%$ & NS \\
Inferior MI & $14 / 17$ & $13 / 16$ & $81 \%$ & $87 \%$ & $<0.001$ \\
SD of phases: & $17 / 35$ & $20 / 25$ & $80 \%$ & $48 \%$ & $<01$ \\
Anterior MI & $6 / 18$ & $7 / 9$ & $78 \%$ & $33 \%$ & $=0.002$ \\
Inferior MI & $11 / 17$ & $13 / 16$ & $81 \%$ & $64 \%$ & $<0.001$ \\
Ejection fraction or & $16 / 35$ & $25 / 25$ & $100 \%$ & $46 \%$ & $\mathbf{N S}$ \\
SD of phases: & $5 / 18$ & $9 / 9$ & $100 \%$ & $30 \%$ & $<0.001$ \\
Anterior MI & $11 / 17$ & $16 / 16$ & $100 \%$ & $65 \%$ & \\
Inferior MI & & & & & \\
\hline
\end{tabular}

‡Ratio of patients with negative radionuclide angiographic test to patients without additional coronary disease.

†Ratio of patients with positive radionuclide angiographic test to patients with additional coronary disease.

$A C D$, additional coronary disease; MI, myocardial infarction.

Table 4 Relation of results of radionuclide angiography to coronary angiography in patients with left anterior descending artery disease

\begin{tabular}{|c|c|c|c|c|}
\hline & No $A C D$ & $A C D$ & Sensitivity & Specificity \\
\hline $\begin{array}{l}\text { Ejection fraction or SD phase: } \\
\text { Inferior MI } \\
\text { Anterior MI }\end{array}$ & $\begin{array}{l}3 / 15 \\
1 / 2 \\
2 / 13\end{array}$ & $\begin{array}{l}14 / 14 \\
7 / 7 \\
7 / 7\end{array}$ & $\begin{array}{l}100 \% \\
100 \% \\
100 \%\end{array}$ & $\begin{array}{l}20 \% \\
50 \% \\
15 \%\end{array}$ \\
\hline
\end{tabular}

Table 5 Clinical, angiographic, and haemodynamic correlates (mean (SD)) in cases with false positive and with true negative and true positive results at radionuclide angiographic testing

\begin{tabular}{|c|c|c|c|}
\hline & False positive & True negative & True positive \\
\hline $\begin{array}{l}\text { Age (years) } \\
\text { Systolic arterial pressure }\left(\mathrm{mm} \mathrm{Hg}^{\mathrm{H}}\right) \\
\text { Diastolic arterial pressure }(\mathrm{mm} \mathrm{Hg}) \\
\text { LAD disease } \\
\text { ^ST elevation } \\
\text { Resting ejection fraction }(\%) \\
\text { Resting SD phase }\left(^{\circ}\right) \\
\text { LVEDP (mm Hg) }\end{array}$ & $\begin{array}{l}47(6 \cdot 8) \\
125(16) \\
80(11) \\
63 \% \dagger \\
80 \% \neq \$ \\
45(16) \\
18(2) \\
14(7)\end{array}$ & $\begin{array}{l}50(6 \cdot 8) \\
125(19) \\
82(14) \\
19 \% \dagger \\
15 \% \ddagger \\
49(12) \\
17(6) \\
13(5)\end{array}$ & $\begin{array}{l}48(9) \\
130(18) \\
85(15) \\
57 \% \\
20 \%(2 / 11) \S \\
52(3) \\
16(1 \cdot 6) \\
15(9)\end{array}$ \\
\hline
\end{tabular}

\#On the resting electrocardiogram.

LVEDP, left ventricular end diastolic pressure; $L A D$, left anterior descending.

Group comparisons: $\nmid p<0.001 ; \ddagger p<0.001 ; \S p<0.002$. 
tional coronary artery stenosis (specificity $66 \%$ ) (Table 3). In patients with anterior $\mathbf{Q}$ waves the sensitivity was $78 \%$ and the specificity was $50 \%$, whereas in the presence of inferior $Q$ waves these values were $81 \%$ and $87 \%$ respectively.

Loss of left ventricular synchronicity as indicated by an increase of the standard deviation of the phases during exercise had a sensitivity of $80 \%$ (77\% for anterior myocardial infarction and $81 \%$ for inferior myocardial infarction) and a specificity of $48 \%(33 \%$ for anterior myocardial infarction and $64 \%$ for inferior myocardial infarction).

If the test was considered to be positive when either the ejection fraction or the standard deviation of the phases criterion was positive, sensitivity increased to $100 \%$ and specificity decreased to $46 \%$ (30\% for anterior myocardial infarction and $65 \%$ for inferior myocardial infarction).

Tables 4 and 5 show that of several different variables, only the presence of left anterior descending artery disease and of ST segment elevation on the resting electrocardiogram were significantly associated with false positive results by radionuclide angiography. All patients with three vessel or left main stem disease were positive at radionuclide angiography and in all of them the ejection fraction decreased on exercise.

\section{Discussion}

The management of symptom free patients several months after an uncomplicated myocardial infarction is a common and yet controversial clinical problem. This study attempts to delineate the prevalence of multivessel disease in this particular subset of patients and to relate the results of the exercise test and of exercise radionuclide angiography to the degree and extent of coronary arterial obstructions.

Many other studies have correlated the results of non-invasive functional tests after myocardial infarction with the coronary angiographic findings, ${ }^{1219-26}$ but most of the authors had conducted their investigations within the first few weeks after the acute episode, when mortality is highest, ${ }^{27}$ and they have examined a mixed population that included both patients with symptoms and those without. Most deaths and cardiac events occur in the first 8-12 weeks after an acute myocardial infarction, and this is the rationale for performing a predischarge exercise test. Such policy, however, is not universal, and patients who are symptom free after an acute myocardial infarction and have not yet been evaluated are often seen in the outpatient clinic several months after the acute episode.
CORONARY ANATOMY

Several groups have studied the extent and distribution of coronary arterial disease in patients after an acute myocardial infarction. Williams et al found multiple vessel disease in $67 \%$ of patients with angina after myocardial infarction. ${ }^{28}$ In a similar population Hamby et al found multivessel disease in $86 \%$ of patients with previous inferior myocardial infarction and in $82 \%$ of patients with previous anterior myocardial infarction. ${ }^{29}$ Turner et al found that $73 \%$ of 61 patients studied within 30 days after an uncomplicated myocardial infarction had multivessel disease. ${ }^{30}$ Miller et al examined 84 patients with previous uncomplicated inferior myocardial infarction who were in functional class NYHA II or III, and found multivessel disease in $80 \%{ }^{31}$ In a similar group of 108 patients with inferior myocardial infarction in NYHA class II or III Chaitman et al found $79 \%$ of multivessel disease. ${ }^{32}$ In a group of symptomatic and asymptomatic patients studied within 6-8 weeks after the acute episode the prevalence of multivessel disease was $63 \%$ in inferior and $42 \%$ in anterior myocardial infarction. ${ }^{21}$ Similarly Gibson et al found multivessel disease in $56 \%$ of 140 patients in Killip class 1-3 who were studied about 11 days after myocardial infarction. ${ }^{22}$ Betriu et al found that $59 \%$ of 259 survivors who were studied one month after myocardial infarction had multivessel disease. ${ }^{33}$

Unlike the groups above we selected only patients who were symptom free two or more months after acute myocardial infarction.

The prevalence of multivessel disease is lower $(42 \%)$ in our population than in previous studies. The longer interval in our study between the acute episode and the time of evaluation may have favoured the occurrence of angina and/or a new acute myocardial infarction in patients with more advanced disease, and such patients would therefore have been excluded. In fact in most of the previous reports asymptomatic and symptomatic patients as well as patients with more than one acute myocardial infarction were studied, and the likelihood of multivessel disease is higher in such a mixed population.

\section{EXERCISE TEST}

In the present study only $10(40 \%)$ of the 25 patients with multivessel disease had $1 \mathrm{~mm}$ or greater depression of the ST segment or angina or both during a maximal treadmill stress test. These results accord with some of the previous studies which showed low sensitivity of stress induced electrocardiographic changes after an acute myocardial infarction. ${ }^{19-23253234-38}$ The low sensitivity of electrocardiographic exercise test may also be due to the large number of patients with anterior $Q$ wave 
myocardial infarction. ${ }^{39}$ The sensitivity of the test improves when analysis is restricted to patients with inferior $\mathrm{Q}$ waves. By an exercise test alone, however, $60 \%$ of our patients with multivessel disease would have been missed. Our results are somewhat at variance with those obtained by others. ${ }^{1240}$ This may be explained by different criteria in the selection of patients and by the time at which electrocardiographic exercise stress test and coronary angiography were performed.

The reduced frequency of positive electrocardiographic exercise stress test after myocardial infarction may be related to the loss of large amounts of viable myocardium, cancellation of electrical forces as a result of diffuse ischaemia, and the presence of ST changes on the resting electrocardiogram, especially in patients with anterior myocardial infarctions.

\section{RADIONUCLIDE ANGIOGRAPHY}

For the evaluation of radionuclide angiographic results we considered two variables-the ejection fraction and the standard deviation of the phases. In normal individuals the ejection fraction is known to increase during exercise. ${ }^{4142}$ The variation of the standard deviation of the phases with exercise is a more controversial concept.

We agree with Ratib et al that the variability of the standard deviation of the phases is due to opposite mechanisms ${ }^{18}-(a)$ an increase is related to the different relative duration of systolic and diastolic phases at rest compared with during exercise and (b) a decrease is due to improved sychronicity of systolic wall motion with exercise. The influence of total acquired counts and of noise on the images is relatively unimportant because first harmonic phase analysis is in itself a heavy low-band filter. In 20 subjects with no evidence of cardiovascular disease we found that the standard deviation of the phases at rest $(16.3(3.6))$ fell significantly on exercise $(10.7$ (2.6)) (unpublished data).

In our population the failure of ejection fraction to increase or an increase in the standard deviation of the phases during exercise were both more sensitive than conventional exercise electrocardiographic changes in detecting residual myocardial ischaemia. Furthermore, all the patients with three vessel disease or with previous inferior myocardial infarction and left anterior descending stenosis were correctly identified. The addition of either of these two criteria substantially increased the sensitivity of radionuclide angiography and all cases with multivessel disease were detected by either of these combinations. Ratib et al reported that the standard deviation of phase can increase even when the ejection fraction response to exercise is normal. ${ }^{18}$ When both criteria were negative multivessel disease could be ruled out in all of our patients.

The specificity of radionuclide angiography studies was lower than that of exercise electrocardiogram criteria especially in patients with previous anterior myocardial infarction. ${ }^{43}$ The presence of left anterior descending disease was significantly associated with false positive responses (Tables 4 and 5). This finding suggests that the integrity of the myocardial territory supplied by the left anterior descending is the major determinant of the increased ejection fraction during exercise. Furthermore in the modified left anterior oblique projection, the territory of the left anterior descending artery is the area of the left ventricle that is nearest the gamma camera crystal, and small variations in end diastolic/end systolic count excursion are better detected in this area than in the rest of the left ventricle. ${ }^{44}$ Therefore exercise induced ischaemia of viable myocardium may also be important in producing false positive responses in this group of patients.

Coronary artery spasm of uninvolved arteries during exercise and underestimation of the extent of coronary artery disease by coronary angiography in the presence of a diffuse atherosclerotic process are other possible explanations for the false positive results of nuclear stress tests.

Finally, the presence of ST elevation in the leads with abnormal $Q$ waves was significantly related to false positive responses (Tables 5 and 6 ) suggesting that aneurysm formation and increased wall tension in the border zone may be an important cause of false positive results. ${ }^{23}$

\section{CLINICAL IMPLICATIONS}

Exercise electrocardiography often failed to identify residual ischaemia in patients who were free from angina 2-12 months after an uncomplicated acute myocardial infarction. In every patient with multivessel disease radionuclide angiography during exercise showed an abnormally low ejection fraction and an increase in the standard deviation of the phases. The percentage of false positives was high, especially in patients with previous anterior myocardial infarction.

None of the patients in whom both radionuclide angiographic criteria were negative had multivessel disease.

Supported in part by a grant from Regione Piemonte.

\section{References}

1 Sobel BE, Breshnahan GF, Shell WE, Yoder RO. Estimation of infarct size in man and its relation to progno- 
sis. Circulation 1982; 46: 640-8.

2 Sanz G, Castaner A, Betriu A, et al. Determinants of prognosis in survivors of myocardial infarction. A prospective clinical angiographic study. $N$ Engl $\mathcal{f}$ Med 1982; 306: 1065-70.

3 Bigger JT, Fleiss JL, Kleiger R, Miller JP, Rolnitzky LM, and the Multicenter Post-Infarction Research Group. The relationship among ventricular arrhythmias, left ventricular dysfunction, and mortality in the 2 years after myocardial infarction. Circulation 1984; 69: 250-8.

4 Martin CA, Thomson PL, Armstrong BK, Hobs MST, De Klerk N. Long-term prognosis after recovery from myocardial infarction: a nine year follow-up of the Perth Coronary Register. Circulation 1983; 68: 961-9.

5 Kitchin AH, Pocock SJ. Prognosis of patients with acute myocardial infarction admitted to a coronary unit. II. Survival after hospital discharge. Br Heart $\mathcal{F}$ 1977; 39: 1167-71.

6 Kannel WB, Sorlie P, McNamara PM. Prognosis after initial myocardial infarction: the Framingam study. $\mathrm{Am}$ f Cardiol 1979; 44: 53-9.

7 Julian DG. Natural history of myocardial infarctionrelevance for secondary prevention. Acta Med Scand 1981; suppl 651: 267-9.

8 Weiblatt E, Goldberg JD, Ruberman W, Frank CW, Monk MA, Chaudhary BS. Mortality after first myocardial infarction: search for a secular trend. $\mathfrak{F} A M A$ 1982; 247: 1576-81.

9 Fioretti P, Brower RW, Simoons ML, et al. Prediction of mortality in hospital survivors of myocardial infarction. Comparison of predischarge exercise testing and radionuclide ventriculography at rest. $\mathrm{Br}$ Heart $\mathcal{F}$ 1984; 52: 292-8.

10 Moss AJ, De Camilla J, Engstrom F, et al. The posthospital phase of myocardial infarction: identification of patients with increased mortality risk. Circulation 1974; 49: 460-6.

11 Bruce RA, Irvin JB. Exercise electrocardiography. In: Hurst JW, Logue RB, Schlant RC, Wenger NK, eds. The heart, arteries and veins, 4th ed. New York: McGraw-Hill, 1978: 336-48.

12 Akhras F, Upward J, Keates J, Jackson G. Early exercise testing and elective coronary artery bypass surgery after uncomplicated myocardial infarction. Effect on morbidity and mortality. Br Heart $\mathcal{f} 1984$; 52: 413-7.

13 CASS principal Investigators and their associates. Coronary artery surgery study (CASS): a randomized trial of coronary artery bypass surgery. Comparability of entry characteristic and survival in randomized patients and nonrandomized patients meeting randomization criteria. 7 Am Coll Cardiol 1984; 3: 114-28.

14 Goris ML, Briandet PA. A clinical and mathematical introduction to computer processing of scintigraphic images. New York: Raven Press, 1983: 19-28.

15 Pavel DG, Zimmer AM, Patterson VN. In vivo labeling of red blood cells with ${ }^{99 m} \mathrm{Tc}$ : a new approach to blood pool visualization. $f$ Nucl Med 1977; 18: 305-8.

16 Tallia R, Morello P, Castellano GC. The WalshHadamard transform: an alternative means of obtaining phase and amplitude maps. F Nucl Med 1984; 25:
608-12.

17 Goris ML, Daspit SG, McLaughlin P, Kriss JP. Interpolative background subtraction. $₹ \mathrm{Nucl}$ Med 1976; 17: $744-7$.

18 Ratib O, Henze O, Schon H, Schelbert HR. Phase analysis of radionuclide ventriculograms for the detection of coronary artery disease. Am Heart $\mathcal{F} 1982$; 104: 1-12.

19 Upton MT, Palmeri ST, Jones RH, Coleman RE, Cobb FR. Assessment of left ventricular function by resting and exercise radionuclide angiocardiography following acute myocardial infarction. Am Heart $\mathfrak{f}$ 1982; 104: 1232-43.

20 Morris DD, Rozanski A, Berman DS; Diamond GA, Swan HJC. Noninvasive prediction of the angiographic extent of coronary artery disease after myocardial infarction: comparison of clinical, bicycle exercise electrocardiographic, and ventriculographic parameters. Circulation 1984; 70: 192-201.

21 DeFeyter PJ, VanEenige MJ, Dighton DH, Visser FC, Dejong J, Roos JP. Prognostic value of exercise testing, coronary angiography and left ventriculography 6-8 weeks after myocardial infarction. Circulation 1982; 66: 527-34.

22 Gibson RS, Watson DD, Craddock GB, et al. Prediction of cardiac events after uncomplicated myocardial infarction: a prospective study comparing predischarge exercise thallium-201 scintigraphy and coronary angiography. Circulation 1983; 68: 321-36.

23 Pulido JI, Doss J, Twieg D, et al. Submaximal exercise testing after acute myocardial infarction: myocardial scintigraphic and electrocardiographic observations. Am f Cardiol 1978; 42: 19-28.

24 Schneider RM, Seaworth JF, Dohrmann ML, et al. Anatomic and prognostic implication of an early positive treadmill exercise test. Am $\mathcal{F}$ Cardiol 1982; 50: 682-8.

25 Dunn RF, Freedman B, Bailey IK, et al. Noninvasive prediction of multivessel disease after myocardial infarction. Circulation 1980; 62: 726-34.

26 Patterson RE, Horowitz SF, Eng C, et al. Can noninvasive exercise test criteria identify patients with left main or three vessel coronary artery disease after a first myocardial infarction? Am f Cardiol 1983; 51: 361-73.

27 Gilpin EA, Koziol JA, Madsen EB, Henning H, Ross J. Periods of differing mortality distribution during the first year after acute myocardial infarction. $\mathrm{Am} \mathfrak{\mathcal { F }} \mathrm{Car}$ diol 1983; 52: 240-4.

28 Williams RA, Cohn PF, Vokonos PS, et al. Electrocardiographic, arteriographic and ventriculographic correlations in transmural myocardial infarction. $A m \boldsymbol{F}$ Cardiol 1973; 31: 595-603.

29 Hamby RI, Hoffman I, Hilsenrath J, et al. Clinical hemodynamic and angiographic aspects of inferior and anterior myocardial infarction in patients with angina pectoris. Am ₹ Cardiol 1974; 34: 513-9.

30 Turner JD, Rogers WJ, Mantle JA, Rackley CE, Russel RO. Coronary angiography soon after myocardial infarction. Chest 1980; 77: 58-65.

31 Miller RR, DeMaria AN, Vismara LA, et al. Chronic stable inferior myocardial infarction: unsuspected harbinger of high-risk proximal left coronary arterial 
obstruction amenable to surgical revascularization. $\mathrm{Am}$ f Cardiol 1977; 39: 954-60.

32 Chaitman BR, Waters DD, Corbara F, Bourassa MG. Prediction of multivessel desease after inferior myocardial infarction. Circulation 1978; 57: 1085-90.

33 Betriu A, Castanero A, Sanz GA, et al. Angiographic finding 1 month after myocardial infarction: a prospective study of 259 survivors. Circulation 1982; 65: 1099-105.

34 Nicod P, Corbett JR, Firth BG, et al. Prognostic value of resting and submaximal exercise radionuclide ventriculography after acute myocardial infarction in highrisk patients with single and multivessel disease. $A m \mathfrak{F}$ Cardiol 1983; 52: 30-6.

35 Bodenheimèr MM, Banka VS, Fooshee CM, Helfant RH. Comparative sensitivity of the exercise electrocardiogram, thallium imaging and stress radionuclide angiography to detect the presence and severity of coronary heart disease. Circulation 1979; 60: 1270-8.

36 Elaerts J, Auloge JP, Blaise C, et al. Valeur predictive de l'epreuve d'effort vis-a-vis des lesions pluritronculaires apres un premier infarctus du myocarde. Arch Mal Coeur 1982; 75: 1085-92.

37 Borer JS, Brensike JF, Epstein E, et al. Limitations of the electrocardiographic response to exercise in predicting coronary artery disease. $N$ Engl f Med 1975; 293: 367-71.
38 Borer JS, Kent KM, Johnston GS, et al. Sensitivity, specificity and predictive accuracy of radionuclide cineangiography during exercise in patients with coronary artery disease. Comparison with exercise electrocardiography. Circulation 1979; 60: 572-80.

39 McMeekin JD, Coop J, Arbor A, et al. Accuracy of radionuclide ventriculography in the diagnosis of coronary disease. $f$ Am Coll Cardiol 1984; 3: 541.

40 Akhras F, Upward J, Stott R, Jackson G. Early exercise testing and coronary angiography after uncomplicated myocardial infarction. $\mathrm{Br} \mathrm{Med} \mathcal{F} 1982 ; 284: 1293-4$.

41 Adam WE, Geffers $H$, Sigel $H$, et al. Evaluation of left ventricular function by radionuclide angiography. Herz 1977; 2: 195-9.

42 Qureshi S, Wagner HN, Alderson PO, et al. Evaluation of left ventricular function in normal persons and patients with heart disease. $f \mathrm{Nucl}$ Med 1978; 19: 135-41.

43 Newman GE, Rerych SK, Upton MT, Sabiston DC, Jones RH. Comparison of electrocardiographic and left ventricular functional changes during exercise. Circulation 1980; 62: 1204-11.

44 Shneider RM, Jaszczak RJ, Coleman RE, Cobb FR. Hypokinesis on radionuclide ejection fraction: compensation using attenuation corrected volumes. $\mathcal{f} \mathrm{Nucl} \mathrm{Med}$ 1984; 25: 747-54. 